\title{
Comparison of Measured Trough Values after Deriving the Initial Dose Setting of Vancomycin with a Conventional Computer Software and a Nomogram Based on the Revised Japanese 2016 Therapeutic Drug Monitoring Guidelines for Antimicrobial Agents
}

\author{
Yasuhiro Kamioka1,2, Hitoshi Suzuki', Masafumi Seki ${ }^{1,2 *}$, Ryusuke Ouchi ${ }^{1}$, Shota Kashiwagura1, \\ Satoshi Koshika1, Yoshiteru Watanabe1 \\ ${ }^{1}$ Division of Pharmacy, Tohoku Medical and Pharmaceutical University Hospital, Sendai, Japan \\ ${ }^{2}$ Division of Infectious Diseases and Infection Control, Tohoku Medical and Pharmaceutical University Hospital, \\ Sendai, Japan \\ Email: ^m-seki@tohoku-mpu.ac.jp, *seki@hosp.tohoku-mpu.ac.jp
}

How to cite this paper: Kamioka, Y., Suzuki, H., Seki, M., Ouchi, R., Kashiwagura, S., Koshika, S. and Watanabe, Y. (2018) Comparison of Measured Trough Values after Deriving the Initial Dose Setting of Vancomycin with a Conventional Computer Software and a Nomogram Based on the Revised Japanese 2016 Therapeutic Drug Monitoring Guidelines for Antimicrobial Agents. Pharmacology \& Pharmacy, 9, 481-487.

https://doi.org/10.4236/pp.2018.911037

Received: October 6, 2018

Accepted: November 12, 2018

Published: November 15, 2018

Copyright $\odot 2018$ by authors and Scientific Research Publishing Inc. This work is licensed under the Creative Commons Attribution-NonCommercial International License (CC BY-NC 4.0). http://creativecommons.org/licenses/by-nc/4.0/

c) (i) \&) Open Access

\section{Abstract}

Background: Due to the relatively high renal toxicity of vancomycin injection (VCM), setting an initial dose that achieves a trough that ranges between 10 and $20 \mu \mathrm{g} / \mathrm{mL}$ on day 3 is important to ensure safety and minimize side-effects, especially for patients with low renal function. To address these issues, the revised 2016 Therapeutic Drug Monitoring (TDM) Guidelines for Antimicrobial Agents (GL2016) proposed the use of a renal function-based, estimate glomerular filtration rate (eGFR) nomogram for setting the dose of VCM in Japan. Methods. Our hospital introduced the use of the GL2016 in September 2016 for the patients administered VCM. After setting the initial VCM dose using 1) a conventional VCM analysis software and 2) the GL2016 eGFR nomogram, the measured trough values on day 3 were compared and evaluated in this study. Results. With the VCM analysis software, the mean measured trough value in the a-total group $(\mathrm{n}=53)$ was $12.8 \pm 4.7 \mu \mathrm{g} / \mathrm{mL}$. With the eGFR nomogram, the mean measured trough value in the b-total group ( $\mathrm{n}=13$ ) was $9.6 \pm 4.6 \mu \mathrm{g} / \mathrm{mL}$. However, when the different severities of renal function were compared, the mean measured trough value was more significantly lower in the b-1 group than in the a-1 group among subjects with G2 and above (eGFR $\geq 60 \mathrm{~mL} / \mathrm{min} / 1.73 \mathrm{~m}^{2}$ ), but it was similar between the a-2 group and the b-2 group among subjects with G3 and below (eGFR < 
$60 \mathrm{~mL} / \mathrm{min} / 1.73 \mathrm{~m}^{2}$ ). The proportion of subjects reaching the various trough ranges shows similar tendency. Conclusions. These data suggested that the measured trough value on day 3 was generally lower when the initial dose was established using the eGFR nomogram based on the GL2016, and this was especially prominent among patients with normal renal function. As for subjects with low renal function, the trough values were relatively high while ensuring safety.

\section{Keywords}

Therapeutic Drug Monitoring (TDM), Vancomycin (VCM), Estimate Glomerular Filtration Rate (eGFR), Guideline 2016 (GL2016), Computer Software

\section{Introduction}

The Therapeutic Drug Monitoring (TDM) Guidelines for Antimicrobial Agents were created by the Japan Society of Chemotherapy and the Japanese Society of Therapeutic Drug Monitoring to ensure that clinical physicians and pharmacists in Japan deliver efficient and appropriate TDM of antimicrobial agents and to provide high quality medical care to patients [1]. The first version of the TDM Guidelines for Antimicrobial Agents was introduced and standardized in August 2012, the revised version, GL2016 was released in June 2016 for practical application [1] [2].

Vancomycin (VCM), which is a drug against methicillin-resistant Staphylococcus aureus, is the most commonly used antimicrobial agent in Japan. However, VCM has numerous side effects that are primarily associated with kidney damage. Therefore, to strike a balance between clinical efficacy and safety, setting the initial dosage and measurement of the trough value on day 3 is mandatory during TDM [1] [2]. To achieve an initial target trough value of 10 to 15 $\mu \mathrm{g} / \mathrm{mL}$ as the dose setting after VCM administration although the trough value of 15 to $20 \mu \mathrm{g} / \mathrm{mL}$ is also acceptable, the GL2016 described the specific dosages according to renal function [1] [2]. Since September 2016, our hospital had been setting the dosage based on the GL2016 and had been measuring trough values.

In this study, after setting the initial VCM dose, we evaluated and compared the measured trough values between 1) an estimate glomerular filtration rate (eGFR) nomogram, as proposed by the GL2016 and 2) a VCM analysis computer software (VCM-soft), which was used prior to the introduction of the GL2016 [2].

\section{Methods}

\subsection{Study Subjects}

The a-total group comprised 53 subjects who used VCM-Soft for initial dose setting between January 2014 and August 2016. The b-total group comprised 13 
subjects who used the initial dose setting proposed by the eGFR nomogram (Table 1) of the GL2016 between September 2016 and March 2017. In addition, the 2012 Clinical Practice Guidebook for Diagnosis and Treatment of Chronic Kidney Disease (CKD) guidelines was used for classifying the severity of renal dysfunction [3]. Groups a-1 and b-1 comprised patients with CKD grade 2 (G2) and above (eGFR $\geq 60 \mathrm{~mL} / \mathrm{min} / 1.73 \mathrm{~m}^{2}$ ) and groups a-2 and b-2 comprised patients with grade 3 (G3) and below (eGFR $<60 \mathrm{~mL} / \mathrm{min} / 1.73 \mathrm{~m}^{2}$ ) (Table 2).

Subjects who received prophylactic administration or those who discontinued the administration prior to measuring the initial blood concentration were excluded.

\subsection{Comparison and Evaluation of the Measured Trough Values after Setting the Initial Dose with the eGFR Nomogram and VCM-Soft}

The measured trough values for each of the $\mathrm{a}$ and $\mathrm{b}$ groups, including the renal function groups, were compared. The trough value ranges were set to 1) less than $10 \mu \mathrm{g} / \mathrm{mL}$, 2) between 10 and $15 \mu \mathrm{g} / \mathrm{mL}$, 3) between 15 and $20 \mu \mathrm{g} / \mathrm{mL}$, and 4) $20 \mu \mathrm{g} / \mathrm{mL}$ and above; the percentage of patients who reached these ranges were compared and evaluated.

In general, an initial target trough value of 10 to $15 \mu \mathrm{g} / \mathrm{mL}$ as the dose setting after VCM administration is ideal although the trough value of 15 to $20 \mu \mathrm{g} / \mathrm{mL}$ is also acceptable.

\subsection{Ethical Considerations}

This study has been approved by the Committee for Clinical Scientific Research of Tohoku Medical and Pharmaceutical University Hospital as No. ID2017-2-030 and -033, and all patients provided written informed consent for use of their blood specimens although measure and estimate of VCM concentration in the blood were specifically focused on part of the routine hospital pharmacological procedure.

Table 1. Vancomycin doses dependent on renal functions recommended by GL2016 in Japan.

\begin{tabular}{|c|c|c|}
\hline $\operatorname{eGFR}\left(\mathrm{mL} / \mathrm{min} / 1.73 \mathrm{~m}^{2}\right)$ & Loading doses (First administration only) & Maintenance doses (/day) \\
\hline$\geq 120$ & $30 \mathrm{mg} / \mathrm{kg}$ & $20 \mathrm{mg} / \mathrm{kg} \times 2$ \\
\hline $90-119$ & $25 \mathrm{mg} / \mathrm{kg}$ & $15 \mathrm{mg} / \mathrm{kg} \times 2$ \\
\hline $80-89$ & $15 \mathrm{mg} / \mathrm{kg}$ & $12.5 \mathrm{mg} / \mathrm{kg} \times 2$ \\
\hline $60-79$ & & $20 \mathrm{mg} / \mathrm{kg} \times 2$ \\
\hline $50-59$ & None & $15 \mathrm{mg} / \mathrm{kg} \times 2$ \\
\hline $30-49$ & & $12.5 \mathrm{mg} / \mathrm{kg} \times 2$ \\
\hline$<30$ & \multicolumn{2}{|l|}{ Not applicable } \\
\hline $\mathrm{HD}$ & $20-25 \mathrm{mg} / \mathrm{kg}$ & $7.5-10 \mathrm{mg} / \mathrm{kg}$ after HD \\
\hline
\end{tabular}


Table 2. Estimated methods and group definitions.

\begin{tabular}{ccc}
\hline Cases and Group & $\begin{array}{c}\text { By Computer soft } \\
\text { (Jan 2014-Aug 2016: } \\
\text { VCM-soft) }\end{array}$ & $\begin{array}{c}\text { By GL2016 } \\
\text { (Sep 2016-Mar 2017: } \\
\text { eGFR-nomogram) }\end{array}$ \\
\hline Total(n) & a-total: 53 cases & b-total: 13 cases \\
Grade $2 \geq^{*}$ & a-1: 38 cases & b-1: 5 cases \\
$\left(\right.$ eGFR $\geq 60 \mathrm{~mL} / \mathrm{min} / 1.73 \mathrm{~m}^{2}$ & a-2: 15 cases & b-2: 8 Cases \\
Grade $3<*$ & (eGFR $\left.<60 \mathrm{~mL} / \mathrm{min} / 1.73 \mathrm{~m}^{2}\right)$ &
\end{tabular}

*indicated by CKD guideline 2012 in Japan (JpnAssc. Kidney).

\subsection{Statistical Analysis}

The clinical and demographic data that were normally distributed were subjected to analysis of variance, with Fisher's exact test for multiple comparisons; those that were non-normally distributed were analyzed by non-parametric statistics, such as the Mann-Whitney U-rank test. When necessary, the results were further corrected using the Bonferroni method. All data were expressed as mean \pm SD. A p-value below 0.05 denoted a statistically significant difference. All analyses were carried out using Stat View software (Abacus Concepts, Cary, NC, USA).

\section{Results}

\section{Comparison and Evaluation of the Measured Trough Values after Setting the Initial Dose with the VCM-Soft and eGFR-Nomogram}

When all the subjects were compared, the mean measured trough value was 12.8 $\pm 4.7 \mu \mathrm{g} / \mathrm{mL}$ for the a-total group and $9.6 \pm 4.6 \mu \mathrm{g} / \mathrm{mL}$ for the b-total group (Figure $1(\mathrm{a})$ ) ( $\mathrm{p}<0.05)$. When comparing groups a-1 and $\mathrm{b}-1$, the mean measured trough value was $13.0 \pm 5.0 \mu \mathrm{g} / \mathrm{mL}$ in the a-1 group and $5.6 \pm 2.9 \mu \mathrm{g} / \mathrm{mL}$ in the $\mathrm{b}-1$ group (Figure $1(\mathrm{~b}))(\mathrm{p}<0.001)$. When comparing groups $\mathrm{a}-2$ and $\mathrm{b}-2$, the mean measured trough value was $12.3 \pm 4.2 \mu \mathrm{g} / \mathrm{mL}$ in the a-2 group and not significantly different in the b-2 group $(12.0 \pm 4.1 \mu \mathrm{g} / \mathrm{mL})$ (Figure $1(\mathrm{c})$ ).

Figure 2 shows the proportion of subjects reaching the various trough ranges. When VCM-soft and the eGFR nomogram were compared in the a-total group, $55 \%$ of the subjects were in the $10-20 \mu \mathrm{g} / \mathrm{mL}$ range and $9 \%$ of the subjects were in the range exceeding $20 \mu \mathrm{g} / \mathrm{mL}$. In contrast, in the b-total group, $39 \%$ of the subjects were in the $10-20 \mu \mathrm{g} / \mathrm{mL}$ range and no subjects exceeded $20 \mu \mathrm{g} / \mathrm{mL}$. When the subjects with G2 and above were compared, the trough value range was $10-20 \mu \mathrm{g} / \mathrm{mL}$ in $55 \%$ and exceeded $20 \mu \mathrm{g} / \mathrm{mL}$ in $11 \%$ of the subjects in the a-1 group, but was $<10 \mu \mathrm{g} / \mathrm{mL}$ in all of the subjects in the b-1 group, suggested the all of the patients in this group might be under the appropriate level.

When the subjects with G3 and below were compared, the trough value range was $10-20 \mu \mathrm{g} / \mathrm{mL}$ in $54 \%$ and exceeded $20 \mu \mathrm{g} / \mathrm{mL}$ in $6 \%$ of the subjects in the a-2 group; in the b-2 group, $63 \%$ had a trough value range of $10-20 \mu \mathrm{g} / \mathrm{mL}$ and none had a trough value that exceeded $20 \mu \mathrm{g} / \mathrm{mL}$. 


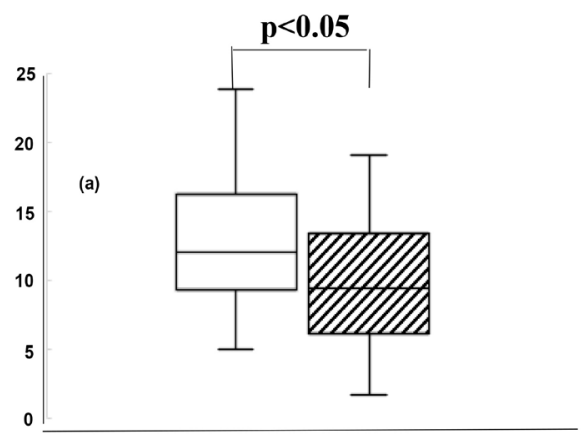

a-total b-total
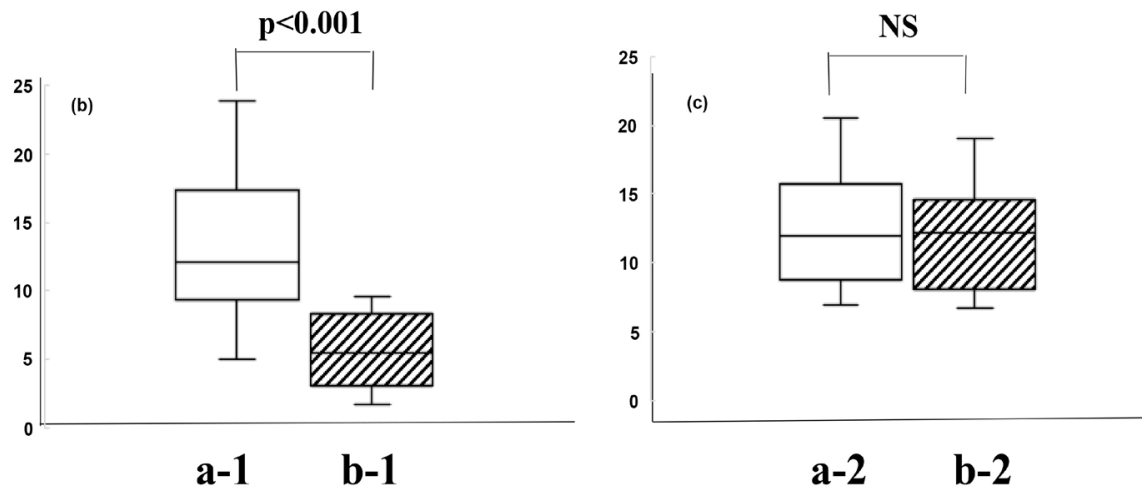

Figure 1. Comparisons of the trough value of VCM on Day 3 between (a) a-total and b-total, (b) a-1 and b-1, and (c) a-2 and b-2, respectively. White bars: VCM-soft groups using by computer soft, and black bars: eGFR-nomogram groups using by nomogram from GL2016, respectively. NS: not significant.

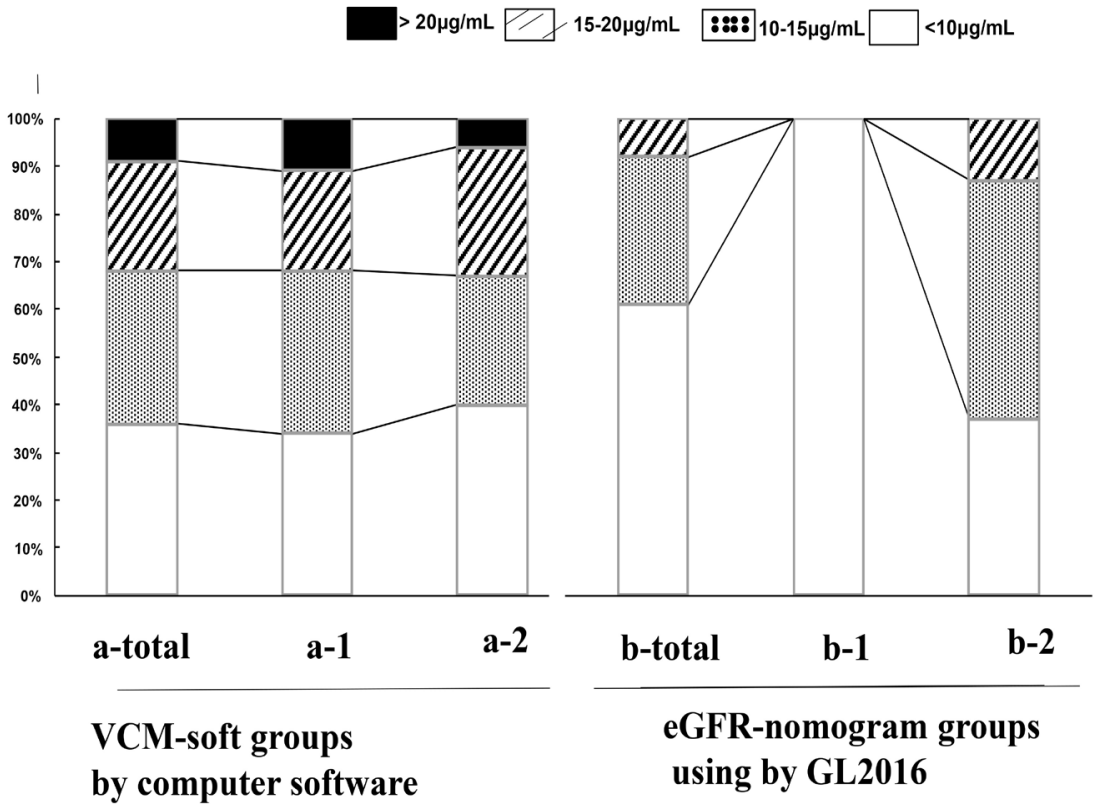

Figure 2. Ratio of the cases dependent on each trough value of VCM on Day 3. They were compared with VCM-soft groups (left) and eGFR-nomogram groups (right), respectively. Black: > $20 \mu \mathrm{g} / \mathrm{mL}$, Stripes: 15 - $20 \mu \mathrm{g} / \mathrm{mL}$, Dots: $10-15 \mu \mathrm{g} / \mathrm{mL}$, and Whites: $<10 \mu \mathrm{g} / \mathrm{mL}$, respectively. 


\section{Discussion}

The GL2016 established an initial target trough value range of 10 to $15 \mu \mathrm{g} / \mathrm{mL}$ as the adequate blood VCM concentration although the trough value of 15 to 20 $\mu \mathrm{g} / \mathrm{mL}$ is also acceptable [2]. The reason was that although $10 \mu \mathrm{g} / \mathrm{mL}$ is needed to achieve clinical efficacy, the levels need to remain below $20 \mu \mathrm{g} / \mathrm{mL}$ to prevent the occurrence of side effects associated with kidney damage. Therefore, approximately $10-20 \mu \mathrm{g} / \mathrm{mL}$ was determined to be the preferred safe and efficient trough value of VCM [1] [2].

When all the subject groups were compared, the mean measured trough values for the b-total group were generally slightly lower compared with a-total group and the adequate blood concentration. In other words, using the GL2016 nomogram increased safety, but it may slightly reduce the clinical efficacy. However, in order to correct this issue, the GL2016 added an amendment that recommended an initial loading dose of VCM that is slightly higher than that given on the first day only in order to enhance clinical efficacy on day 1 [2].

According to the CKD guidelines 2012, CKD was defined as a disorder of the kidney, such as proteinuria, or a persistent eGFR of $<60 \mathrm{~mL} / \mathrm{min} / 1.73 \mathrm{~m}^{2}$ for 3 or more months; this definition had been used for the analysis of various renal functions [3]. When patients with different severities of renal dysfunction were compared, the groups with low renal function (i.e., G3 and below) had trough levels within the range of adequate blood concentration. Therefore, the can be said that the GL2016 ensured safety, which was the foremost concern in the past among patients with low renal function.

However, comparison of subjects with relatively stable renal function (i.e., G2 and above) showed that the VCM blood concentration was adequate in the a-1 group but was significantly lower in the b-1 group. Masuda et al. retrospectively calculated the eGFR of patients after setting the initial VCM dosage using the VCM-soft and evaluated the efficacy and safety of the dosage recommended by the nomogram [4]. However, they suggested that an eGFR between 30 and 80 $\mathrm{mL} / \mathrm{min} / 1.73 \mathrm{~m}^{2}$ may not reach an adequate blood concentration. Suzuki et al. retrospectively examined the degree of reaching trough levels in the GL2016 group and found that $27.9 \%$ of the subjects in the TDM implementation group had reached a range between 10 and $15 \mu \mathrm{g} / \mathrm{mL}$, which was similar to the results of the present study (31\%) [5]. However, in their study, $11.6 \%$ of the subjects had trough levels that exceeded $20 \mu \mathrm{g} / \mathrm{mL}$, which was different from the results of the present study. The reasons of these differences may be dependent on the differences of the patients' backgrounds, including ages.

\section{Conclusion}

Safety can be assured when using the GL2016 for initial dose setting of VCM; however, there may be a slight decline in clinical efficacy among healthy adults. Although GL2016 was optimal for the patients with lower renal functions, future studies on a larger number of cases will be needed to re-examine the loading 
method in patients with normal renal function.

\section{Acknowledgements}

This work was supported by a Grant-in-Aid for Scientific Research (17K09623 to M.S.) from the Japanese Society for the Promotion of Science.

\section{Conflicts of Interest}

The authors declare no conflicts of interest regarding the publication of this paper.

\section{References}

[1] Matsumoto, K., Takesue, Y., Ohmagari, N., et al. (2013) Practice Guidelines for Therapeutic Drug Monitoring of Vancomycin: A Consensus Review of the Japanese Society of Chemotherapy and the Japanese Society of Therapeutic Drug Monitoring. Journal of Infection and Chemotherapy, 19, 365-380. https://doi.org/10.1007/s10156-013-0599-4

[2] Matsumoto, K., Takesue, Y., Ohmagari, N., et al. (2016) Revised Practice Guidelines for Therapeutic Drug Monitoring of Vancomycin: A Consensus Review of the Japanese Society of Chemotherapy and the Japanese Society of Therapeutic Drug Monitoring. Japanese Journal of Chemotherapy, 1, 1-120. (In Japanese)

[3] Japanese Society of Nephrology (2012) Clinical Practice Guidebook for Diagnosis and Treatment of Chronic Kidney Disease. Japanese Journal of Nephrology, 54, 1031-1191.

[4] Masuda, N., Maiguma, T., Komoto, A., Haruki, Y., Sugiyama, T. and Teshima, D. (2017) Validation of Vancomycin Nomogram Using eGFR to Calculate Initial Dosages as Stated in the TDM Guideline for Antibiotics 2016: Study in Patients with Mild to Moderate Renal Dysfunction. The Japanese Journal of Therapeutic Drug Monitoring, 34, 132-136.

[5] Suzuki, A., Tanaka, H., Namiki, M., Ikeda, H., Kogo, M. and Sasaki, T. (2017) Impact of Trough Concentration for Vancomycin Therapy with Initial Dosage. Japanese Journal of Environmental Infections, 32, 250-257. https://doi.org/10.4058/jsei.32.250 